\title{
Complex partial seizures: EEG foci and response to carbamazepine and sodium valproate
}

\author{
AK GUPTA, PM JEAVONS \\ From Dudley Road Hospital, and The Clinical Neurophysiology Unit, University of Aston, Birmingham, UK
}

SUMMARY The EEG and clinical records were reviewed of 85 subjects who had been treated for complex partial seizures with carbamazepine alone or with a combination of carbamazepine and sodium valproate. There was a correlation between the site of the EEG abnormality and the therapeutic response to anticonvulsant therapy. Subjects who had a left sided temporal lobe EEG abnormality responded better to carbamazepine alone, while those who had an abnormality on the right responded to a combination of carbamazepine and sodium valproate.

It has been well documented that the site of temporal lesions plays a vital role in the symptomatology of complex partial seizures. ${ }^{1-4}$ In an earlier study we reported that autonomic and psychic auras are more frequently associated with right sided temporal lobe lesions. ${ }^{5}$ A similar observation has also emerged from studies of other workers. ${ }^{6-8}$ Recently there have been a few reports where the site of temporal lobe lesions was correlated with certain neuropsychiatric disorders. ${ }^{29-13}$ Despite this, very little information is available about the appropriate choice of anticonvulsant therapy, although several reports have indicated that carbamazepine is the drug of choice in partial epilepsies ${ }^{14-17}$ and valproic acid in generalised seizures. ${ }^{18-22}$ However, other than the work of Shakir et al, ${ }^{13}$ Callaghan $e t a{ }^{24}$ and Richens, ${ }^{25}$ there have been no comparative studies of the two drugs in the treatment of partial epilepsies. Earlier reports in the literature suggested that sodium valproate was less effective in the treatment of partial epilepsy, and of little value in complex partial seizures. ${ }^{26-27}$ It is difficult to explain how one particular anti-convulsant agent is effective in one kind of seizure but fails to provide any benefit in other types of epilepsy.

Is this variation in drug response in different types of seizures due to a certain hidden neurochemical factor, or does the site of temporal lobe lesions have some influence on the drug response? It is with this hypothesis that we evaluated the drug response in cases of adult complex partial seizures who were

Address for reprint requests: Dr AK Gupta, EEG Department, Dudley Road Hospital, Birmingham B18 7QH, UK

Received 15 December 1984 and in revised form 21 February 1985. Accepted 2 March 1985 treated with carbamazepine alone or in combination with sodium valproate and attempted to correlate the treatment outcome with the site of temporal lobe lesions.

\section{Materials and methods}

We reviewed the clinical records of 85 subjects who were treated for their complex partial seizures between 19781981 in an out-patient epilepsy clinic. These subjects were treated with carbamazepine alone, or in combination witho sodium valproate for a period of 4 years. There were 375 females and 48 males. The age range was 9-52 years. Mosto patients had a long history of epilepsy, the mean duration? being 14.7 years. The minimum length of follow up was 3 years. Each patient had a detailed clinical and neurological examination at the time of the first visit. The clinical characteristics of the whole group are given in table 1 .

EEGs were taken on a 16-channel machine with the International 10/20 electrode placement system, and the records were examined visually by one of us. The lateralisation of EEG abnormalities was based on the findings of localised sharp waves, spikes or slow waves alone, or in combination.

Anti-epileptic drugs were administered twice daily, carbamazepine being the first drug of choice. If patients were already receiving other anti-epileptic drugs these were gradually withdrawn after carbamazepine had been introduced slowly in increments of $\mathbf{2 0 0} \mathbf{m g}$ every one or two weeks. If complete control of seizures was not achieved, sodium valproate was added. The dose of carbamazepine was based either on response to therapy or on body weight, using $15-20 \mathrm{mg} / \mathrm{kg} /$ body weight as a guide, whilst for sodium valproate the guide dose was $25-30 \mathrm{mg} / \mathrm{kg} /$ body weight. Therapy was monitored with serum levels and all patients had biochemical and haematological investigations. All patients were followed up initially at monthly intervals, then at 3 or 4 months, and subsequently at 6 monthly intervals. Patients kept a record of all their forms 
Table 1 Clinical data of the studied group

\begin{tabular}{|c|c|c|c|c|}
\hline \multirow[t]{2}{*}{ Characteristic } & \multirow[t]{2}{*}{ No of patients } & \multicolumn{3}{|c|}{ Site of temporal lobe lesion } \\
\hline & & Right & Left & Bilateral \\
\hline $\begin{array}{l}\text { Birth anoxia } \\
\text { Subnormality } \\
\text { Neurological handicap } \\
\text { Psychiatric handicap } \\
\text { Febrile convulsion } \\
\text { Attacks related to menstrual cycle } \\
\text { Mean duration of epilepsy (yr) }\end{array}$ & $\begin{array}{r}1 \\
4 \\
1 \\
7 \\
3 \\
11\end{array}$ & $\begin{array}{c}-1 \\
- \\
4 \\
1 \\
5 \\
15 \cdot 5\end{array}$ & $\begin{array}{c}1 \\
3 \\
1 \\
3 \\
2 \\
5 \\
15 \cdot 27\end{array}$ & $\begin{array}{l}\bar{z} \\
= \\
\overline{1} \\
14 \cdot 15\end{array}$ \\
\hline
\end{tabular}

of seizures on a fit progress chart and improvement was assessed on the basis of this chart and on clinical interview. Those subjects who remained free from all types of seizures, either on monotherapy or in a combination of carbamazepine and sodium valproate were regarded as being completely controlled. Subjects in whom seizures were either reduced or had improved in severity, were included in the category of uncontrolled subjects. No patient was assessed until the seizure-free interval was greater than had been on previous medication.

\section{Results}

The EEG abnormality was left sided in 37 subjects, right sided in 33 and bilateral in 15 subjects. The mean duration of epilepsy was 15 years in those with right or left temporal lobe abnormality and 14 years in those with bilateral EEG abnormalities.

Complete control was obtained with carbamazepine as a sole agent in $\mathbf{4 0}$ patients (table 2), of whom 24 had a left temporal EEG abnormality, seven had a right sided abnormality and nine had a bilateral abnormality.

In 45 patients (table 3) complete control of seiz- ures was not achieved. Of these 45,26 had a right sided abnormality, 13 had a left sded abnormality and 6 had a bilateral abnormality. The addition of sodium valproate to the medication of these 45 subjects resulted in control of all seizures in 22 (table 3 ). Of these 22 patients on co-medication with carbamazepine and sodium valproate, the EEG abnormality was right sided in 18 patients, left sided in one and bilateral in three. Of those 23 patients who did not respond to co-medication, 12 had an EEG abnormality on the left, eight had right sided abnormalities and in three the abnormality was bilateral. The average length of seizure-free period either on monotherapy or with a combination of carbamazepine and sodium valproate at the time of final assessment in completely controlled subjects, was 31 months.

The dosage and serum levels are shown in table 4. In subjects who were seizure-free on carbamazepine as the sole drug of treatment, the serum carbamazepine levels were not significantly different between those who responded to treatment and those who did not $(t=1 \cdot 326$, NS). In the subse-

Table 2 Response to carbamazepine therapy and the site of the EEG abnormality

\begin{tabular}{|c|c|c|c|}
\hline \multirow[t]{2}{*}{ Therapy } & \multicolumn{3}{|c|}{ Site of the EEG abnormality } \\
\hline & Right temporal ${ }^{*}$ & Left temporal ${ }^{*}$ & Bilateral \\
\hline \multirow{2}{*}{$\begin{array}{l}\text { Controlled with carbamazepine } \\
\text { alone } \\
\text { Not controlled with } \\
\text { carbamazepine alone }\end{array}$} & 7 & 24 & 9 \\
\hline & 26 & 13 & 6 \\
\hline
\end{tabular}

$x^{2}=13.4(\mathrm{p}<0.001)$

Table 3 Response to the combination therapy with carbamazepine and sodium valproate in previously uncontrolled patients and the site of EEG abnormality

\begin{tabular}{llll}
\hline Therapy & Site of the EEG abnormality & & Bilateral \\
\cline { 2 - 4 } & Right temporal & Left temporal & \\
\hline $\begin{array}{l}\text { Controlled with carbamazepine } \\
\text { and sodium valproate }\end{array}$ & 18 & 1 & 3 \\
$\begin{array}{l}\text { Not controlled with } \\
\text { carbamazepine and sodium } \\
\text { valproate }\end{array}$ & 8 & 12 & 3 \\
\hline
\end{tabular}

${ }^{*} \chi^{2}=12.9(\mathrm{p}<0.001)$ 
Table 4 Anticonvulsants: dosage and serum levels related to therapeutic response

\begin{tabular}{|c|c|c|c|c|}
\hline & \multicolumn{2}{|l|}{ Daily dose ( $\mathrm{mg} / \mathrm{kg} / \mathrm{bw})$} & \multicolumn{2}{|c|}{ Serum levels (mg/l) } \\
\hline & Range & Mean & Range & Mean \\
\hline $\begin{array}{l}\text { All seizures controlled on carbamazepine } \\
\text { alone } \\
\text { Not controlled on carbamazepine alone }\end{array}$ & $\begin{array}{l}10-31 \\
14-27.5\end{array}$ & $\begin{array}{l}18 \pm 5 \\
21 \pm 4\end{array}$ & $\begin{array}{l}5-16 \\
5-15\end{array}$ & $\begin{array}{l}10 \cdot 5 \pm 3^{*} \\
9 \cdot 8 \pm 3^{*}\end{array}$ \\
\hline $\begin{array}{l}\text { All selzures controlied on carbamazepine } \\
\text { Sodium vaproate }\end{array}$ & $\begin{array}{l}\text { and sodium valproate: } \\
9-25 \cdot 5 \\
10-36\end{array}$ & $\begin{array}{l}16 \cdot 5 \pm 5 \\
23 \pm 5 \dagger\end{array}$ & $\begin{array}{l}3-15 \cdot 5 \\
26-137\end{array}$ & $\begin{array}{l}8 \cdot 8 \pm 2 \cdot 6 \dagger \\
59 \pm 21 \ddagger\end{array}$ \\
\hline $\begin{array}{l}\text { Not controlled on carbamazepine and sod } \\
\text { Carbamazepine } \\
\text { Sodium valproate }\end{array}$ & $\begin{array}{l}\text { lium valproate: } \\
11 \cdot 4 \pm 28 \\
15-63\end{array}$ & $\begin{array}{l}20 \pm 4 \\
33 \pm 12 \S\end{array}$ & $\begin{array}{r}5-14 \cdot 5 \\
31-169\end{array}$ & $\begin{array}{l}9 \cdot 2 \pm 2 \cdot 3 \dagger \\
72 \pm 28 \ddagger\end{array}$ \\
\hline
\end{tabular}

$*_{\mathrm{t}}=1.326, \mathrm{NS} ; \mathrm{tt}=1.266, \mathrm{NS} ; \ddagger \mathrm{t}=3.371 \mathrm{p}<0.001 ; \S \mathrm{p}<0.001$.

quent group of patients who failed to respond to carbamazepine but became seizure-free on adding sodium valproate, the serum carbamazepine levels were, not surprisingly, different in patients who did not respond from those who did $(t=1 \cdot 266$, NS). However, the serum levels of valproic acid were significantly lower in patients who did respond compared to patients who did not $(t=3.371 \mathrm{p}<0.001)$.

\section{Discussion}

Although there are certain drawbacks in our study, such as lack of a control sample and the absence of a comparative group of patients with sodium valproate as a sole drug of treatment, our results indicate that patients with an active epileptogenic focus in the left temporal lobe respond better to carbamazepine. Patients with an abnormality on the right respond better to a combination of carbamazepine and sodium valproate. This variation in the response to drug treatment and site of the temporal lobe lesion is difficult to explain.

Table 2 shows that more than $60 \%$ of the subjects with a left temporal abnormality responded to carbamazepine compared to only $12 \%$ in whom the abnormality was on the right. It is also interesting to note that when sodium valproate was added in uncontrolled subjects $(N=45)$, only 22 responded and the majority of them had an abnormality in the right temporal lobe $\left(\chi^{2}-12.9 ; p<0.001\right)$.

Available literature on the drug treatment of complex partial seizures indicates that carbamazepine is effective but opinions vary as to the value of sodium valproate. Thus, Jeavons and Clarke $^{27}$ reported that sodium valproate was of limited value in the treatment of temporal lobe epilepsy. Livingston $e a{ }^{28}$ did not find valproic acid beneficial against psychomotor seizures. However, Harwood and Harvey ${ }^{29}$ showed a $90 \%$ reduction in fit frequency in $32 \%$ of their patients treated with sodium valproate for temporal lobe seizures.

Coutler $e a^{30}$ in a study based upon 100 children with different types of epilepsy, concluded that valproic acid may be useful in complex partial seizures when other drugs failed to control seizures adequately. A similar view was expressed by other workers. Turnbull $e t a^{31}$ compared the effect of sodium valproate and phenytoin in the treatment of 51 patients with partial epilepsy and found both drugs similar in efficacy, sodium valproate being slightly more effective. Bruni and Albright ${ }^{32}$ found that $50 \%$ of patients with complex partial seizures had a significant reduction in the number of seizures when treated with sodium valproate. However, the long $-\frac{\mathbb{\Phi}}{2}$ term benefit was very limited as half of those whoo responded showed an increase in seizure frequencyo after the 3 month period. These workers also con? cluded that the long-term efficacy of sodium valproate depended to a certain extent upon the pre-drug seizure frequency.

We were unable to observe any significant rela tionship between the serum carbamazepine levels of controlled and uncontrolled patients, while they were on carbamazepine alone or while being treated with a combination of carbamazepine and sodium valproate. However, our results clearly indicate significantly higher serum valproic acid levels in patients who did not respond to a combination of carbamazepine and sodium valproate, than those who became seizure free on this combination (table 4). The possible explanation for the higher serum levels of valproic acid in uncontrolled subjects is that there is a tendency for the clinician to increase the dose far above the maximum recommended dosages, in the hope that this will control the seizures. This explanation, to a certain extent, is true for our own uncontrolled patients, as the mean daily dose of sodium valproate was significantly higher in those not controlled, compared with those controlled with carbamazepine and sodium valproate $(p<0.001)$. Goggin $e a a^{33}$ also noticed a similar tendency for higher valproic acid levels in their sample of poorly controlled patients with different types of seizures, treated with sodium valproate alone. 
From the literature on the drug treatment of complex partial seizures, it can be seen that the results differ from subject to subject and according to the type of sample in the drug trial, and the nature of the seizure, and duration of epilepsy.

The results of this study indicate that both carbamazepine and sodium valproate are effective in the treatment of complex partial seizures, but the outcome of the drug treatment in our sample depends, to a certain extent, upon the site of the active epileptogenic focus, for which we have no explanation.

We are grateful to our colleagues for referring patients to the Epilepsy Clinic. We appreciate the skill of our technicians who carried out all the EEG investigations at Dudley Road Hospital and Newcross Hospital and to Miss B Hill and Mrs D Thomas for their excellent secretarial assistance.

\section{References}

' Feindel W, Penfield $\mathrm{W}$. The localization of discharge in temporal lobe automatism. Arch Neurol Psychiatry (Chicago) 1976;72:605-30.

${ }^{2}$ Hughes JR, Schlagenhauf RE, Curtin MJ, Brown VP. Electro-clinical correlation in temporal lobe epilepsy with emphasis on inter-areal analysis of the temporal lobe. Electroencephalogr Clin Neurophysiol 1961;13:333-9.

${ }^{3}$ Remillard GM, Andermann F, Gloor P, Oliver A, Martin JB. Water drinking as ictal behaviour in complex partial seizures. Neurology (NY) 1981;31:117-24.

${ }^{4}$ Roberts JKA, Robertson MM, Trimble MR. The lateralising significance of hypergraphia in temporal lobe epilepsy. J Neurol Neurosurg Psychiatry 1982; 45: 131-8.

s Gupta AK, Jeavons PM, Hughes RC, Covanis A. Aura in temporal lobe epilepsy: clinical and electroencephalographic correlation. J Neurol Neurosurg Psychiatry 1983;46:1070-83.

- Van Buren JM, Ajmone-Marsan C. A correlation of autonomic and EEG components in temporal lobe epilepsy. Arch Neurol 1960;3:683-93.

7 Van Buren JM. The abdominal aura: A study of abdominal sensations occurring in epilepsy and produced by depth stimulator. Electroencephalogr Clin Neurophysiol 1963;15:1-19.

${ }^{8}$ Penfield W, Perot P. The brain's record of auditory and visual experience. A final summary and discussion. Brain 1963;86:595-6.

${ }^{4}$ Gainotti G. Emotional behaviour and the hemispheric side of the lesion. Cortex 1972;5:41-55.

${ }^{10}$ Milner B. Disorders of learning and memory after temporal lobe lesions in man. Clin Neurosurg 1971;19:421-46.

"Shukla GD, Katiyar BC. Psychiatric disorders in tem- poral lobe epilepsy: The laterality effect. $\mathrm{Br} J$ Pिsychiatry 1980;137:181-2.

${ }^{12}$ Sherwin I. Psychosis associated with epilepsy: significance of the laterality of the epileptogenic lesion. J Neurol Neurosurg Psychiatry 1981;44:83-5.

${ }^{13}$ Levine DN, Finkestein S. Delayed psychosis after right temporoparietal stroke or trauma: Relation to epilepsy. Neurology (NY) 1982;32:267-73.

${ }^{14}$ Rodin EA, Rim CS, Rennick PM. The effects of carbamazepine on patients with psychomotor epilepsy: reults of a double-blind study. Epilepsia 1974; 15:547-61.

is Cereghino JJ, Brock JT, Van Meter JC, Penry JL, Smith LD, White BG. Carbamazepine for epilepsy. Neurology (Minneap) 1974;24:401-10.

${ }^{16}$ Strandjord RE, Johananessen SI. Single drug therapy with carbamazepine in patients with epilepsy: serum levels and clinical effects. Epilepsia 1980;21:655-62.

${ }^{17}$ Mikkelsen B, Berggreen P, Joensen P, Kristensen O, Kohler O, Mikkelsen BO. Clonazepam and carbamazepine in psychomotor epilepsy: a randomized multicentre trial. Epilepsia 1981;22:415-20.

${ }^{18}$ Simon D, Penry JK. Sodium D-N-Propylacetate (DPA) in the treatment of epilepsy. A review. Epilepsia 1975; 16:549-73.

${ }^{14}$ Pinder RM, Brogden RN, Speight TM, Avery GS. Sodium valproate: a review of its pharmacological properties and therapeutic effects in epilepsy. Drugs 1977;13:81-123.

${ }^{20}$ Bruni J, Wilder BJ, Bauman AW, Willmore LJ. Clinical efficacy and long-term effects of valproic acid therapy on spike-and-wave discharges. Neurology (Minneap) 1.980;30:42-6.

${ }^{21}$ Covanis A, Gupta AK, Jeavons PM. Sodium valproate: Monotherapy and polytherapy. Epilepsia 1982;23:693-720.

${ }^{22}$ Feuerstein J. A long term study of monotherapy with sodium valproate in primary generalised epilepsy. $\mathrm{Br} \mathrm{J}$ Clin Pract (Symp Suppl) 1983;27:17-25.

${ }^{23}$ Shakir RA, Johnson RH, Lambie DG, Melville ID, Nanda RN. Comparison of sodium valproate and phenytoin as single drug treatment in epilepsy. Epilepsia 1981;22:27-33.

${ }^{24}$ Callaghan N, Rose AK, O' Neill B, Crowley M, Goggin T. A comparative study between carbamazepine, phenytoin and sodium valproate in monotherapy in previously untreated and recently diagnosed patients with epilepsy: a preliminary communication. Br J Clin Pract (Symp Suppl) 1983;27:7-9.

${ }^{25}$ Richens A. Comparative multicentre study of sodium valproate and carbamazepine in adult-onset epilepsy: Progress report. Br J Clin Pract (Symp Suppl) 1983;27:14-16.

${ }^{26}$ Haigh D, Forsythe WI. The treatment of childhood epilepsy with sodium valproate. Dev Med Child Neurol 1975; 17:743-8.

${ }^{27}$ Jeavons PM, Clark JE. Sodium valproate in the treatment of epilepsy. $\mathrm{Br}$ Med J 1974;2:584-6.

${ }^{28}$ Livingston S, Pauli LL, Price I, Kramer II. Valproic acid in epilepsy. JAMA 1979;24:1892.

${ }^{24}$ Harwood G, Harvey PKP. Results of a clinical trial on the use of Epilim in convulsive disorders, with special 
reference to its efficacy in temporal lobe attacks with focal features. In: Legg NJ, ed. Clinical and pharmacological aspects of sodium valproate (Epilim) in the treatment of epilepsy. Tunbridge Wells: MCS Consultants, 1976:40-8.

${ }^{30}$ Coulter DL, Wu H, Allen RJ. Valproic acid therapy in childhood epilepsy. JAMA 1980;244:785-8.

${ }^{31}$ Turnbull DM, Rawlins MD, Weightman D, Chadwick DW. Long term comparative study of phenytoin and valproate in adult onset epilepsy. Br J Clin Pract
(Symp Suppl) 1983;27:3-6.

${ }^{32}$ Bruni J, Albright P. Valproic acid therapy for complex partial seizures: Its efficacy and toxic effects. Arch Neurol 1983; 40:135-7.

${ }^{33}$ Goggin T, Crowley M, Callaghan N. Comparative study of serum levels related to seizure control of sodium valproate, phenytoin and carbamazepine as monotherapy in the treatment of recently diagnosed epileptic patients. Br J Clin Pract (Symp Suppl) 1983;27:10-13. 